\title{
The Optimal Timing of Unemployment in a Recession
}

THE HIGH unemployment in 1975 and the possibility that it will persist for several years raise in very stark terms the issues of the inflation-unemployment tradeoff. One aspect of this question, which has been debated extensively in the past decade, regards the social costs of inflation and unemployment: whether macroeconomic policymakers should strive for lower inflation rates or lower unemployment rates, recognizing that they cannot achieve both at the same time and may not be able to achieve a satisfactory level of either. A neglected aspect, which nevertheless deserves attention, regards the "optimal" time path of unemployment in a recession -optimal, that is, from the standpoint of reducing inflation per manhour of unemployment experienced in the recession. Since the one social value of a recession is its ability to stop inflation, some time paths for unemployment must achieve this objective more efficiently than others. This paper examines the timing issue. ${ }^{1}$

Note: This paper purports to answer a question raised at the dinner discussion of the Brookings panel in December 1974. I have benefited from discussions with Roger Craine and several members of the Brookings panel. I also thank Douglas Battenberg for simulating the SMP model.

1. There have been some recent debates on this issue in connection with the politically ill-fated "long-run economic projections" in the budget document for fiscal 1976 (see The Budget of the United States Government, Fiscal Year 1976, p. 41). These projections had the unemployment rate remaining in the vicinity of 8 percent through the end of 1976 and still as high as 6 percent as late as 1979-inspiring questions of whether this much unem- 
To ask how unemployment can best be timed to minimize inflation means assuming that macroeconomic policymakers can control the rate of unemployment, at least over some horizon. Such an assumption is patently untrue for periods as short as a quarter, and recent events have taught that it may be a dubious proposition even for one year. Yet, granting that, most economists would still agree that as long as the unemployment rate remains above some frictional level-as it clearly would in a recession-its shortrun course can be influenced by monetary and fiscal policies. And then the questions about timing that this paper addresses do become relevant: Should policymakers let the unemployment rate rise sharply and then try to bring it back down sharply (a V-shaped recession, in current parlance)? Try to maintain it at approximately the same level for a period of time (a saucer-shaped recession)? Let it rise sharply and bring it back down slowly (a skewed V)? Simply ignore timing? Given today's problem-a recession during which the unemployment rate has already risen sharply-the analysis of the paper can be altered slightly to ask how much more inflation will be created in a fast, as opposed to a slow, recovery.

The paper has both a theoretical and an empirical component. In the theoretical section, I assume that policymakers are resigned to accepting some average level of unemployment for the next five years, but that each year they alter its rate so as to minimize rates of inflation over an undetermined time horizon. ${ }^{2}$ While they can control year-to-year changes in the

ployment was necessary, and whether it was necessary for such a long time. In a more technical vein, back in 1949, Thomas C. Schelling discussed whether it was better to get recessions over with quickly or drag them out, but he was concerned with the response of private spending demands to rates of price change; see Schelling, "The Dynamics of Price Flexibility," American Economic Review, vol. 39 (September 1949), pp. 911-22. Later, Edmund S. Phelps used control theory to compute optimal rates of unemployment and inflation in a very long-run context, in "Phillips Curves, Expectations of Inflation and Optimal Unemployment over Time," Economica, vol. 34 (August 1967), pp. 254-81. This type of analysis was extended in various directions and quantified by Robert $\mathrm{E}$. Hall, "The Phillips Curve and Macroeconomic Policy," in Karl Brunner and Allan Meltzer (eds.), The Phillips Curve and Labor Markets (Amsterdam: North-Holland, 1975); and by C. D. MacRae and E. C. MacRae, "Adaptive Control of Inflation and Unemployment," in NEREM Record, vol. 12, Northeast Electronics Research and Engineering Meeting, 1970 (Boston Section, Institute of Electrical and Electronics Engineers, 1970) (Urban Institute Reprint). The paper also bears some similarity to the literature on the political business cycle. See, for example, William D. Nordhaus, "The Political Business Cycle," Review of Economic Studies, vol. 42 (April 1975), pp. 169-90.

2. As it turns out, the analysis reaches identical conclusions if it is reversed-that is, if unemployment is minimized for a given five-year level of inflation. The problem can 
unemployment rate, policymakers cannot alter the short- or long-run relationship between unemployment and inflation, and they must try to achieve macro goals within this constraint. The paper shows how the optimal path of unemployment in these five years varies with a series of real-world complications-nonlinearities in the short-run tradeoff, adaptive expectations of inflation, and varying time horizons for fighting inflation. The empirical section then elaborates on these results by computing optimal unemployment paths for the next five years given by one commonly used empirical model of the price-wage process-that of the SMP (SSRC-MIT-Penn) econometric model-and, with the same model, estimating how much inflation can be reduced over the five years if the optimal path is taken.

\section{Minimizing Rates of Inflation for Five Years}

The problem of finding the optimal path for unemployment involves balancing two influences acting in opposite directions. On the one hand, the underlying nonlinearity in the inflation-unemployment tradeoff, which makes high unemployment rates relatively less effective in fighting inflation, encourages policymakers to spread unemployment evenly across the five years. With a given "dose" of unemployment to administer over a five-year period, they prefer not to give more than one-fifth in any one year because, at the margin, extra unemployment would be less effective in fighting inflation in that year. On the other hand, the influence of past price changes on current inflation pushes them toward killing inflation promptly by taking more unemployment now than later, because any inflation that is killed now means that much less fuel for inflation in future years. The optimization exercise works out the appropriate compromise between these two conflicting forces.

Assume first that the nation has a President who wants to minimize the sum of the inflation rates in each of the next five years, but does not care what happens after that time. His implicit loss function is

$$
L=\sum_{i=1}^{5} \frac{\Delta P_{i}}{P_{i-1}},
$$

be set up either way, but the one I have chosen is more in keeping with the spirit of empirical work in the Phillips curve, which makes unemployment the independent (leading) variable and inflation the dependent (lagging) variable. 
where $L$ represents the expression to be minimized and $P$ is some aggregate price level. This would be almost the same as minimizing the growth in prices over the next five years, $\left(P_{5}-P_{0}\right) / P_{0}$, the sole difference being that the annualized target scales down absolute changes in the later years since price levels are higher by that time. This loss function could be elaborated to allow for the effects of initial conditions, nonlinear penalties for high or unexpected rates of inflation, or the scaling down of later price changes through a time-preference discount rate, but this President does not worry about such complications. For now, I assume that a given reduction in inflation is as desirable to him in 1979 as in 1975.

The inflation-unemployment relationship used here is a standard nonlinear tradeoff, modified to take account of criticisms raised against simple tradeoff functions because they ignore the following elements:

1. There is an undetermined parameter that establishes the nonlinearity, or the relative impact of high and low unemployment rates in reducing inflation.

2. The tradeoff between inflation and unemployment can also be shifted in the short run, and possibly eliminated in the long run, through a set of lagged price-change terms. These could represent adaptive expectations of inflation, cost-of-living provisions, difficulties in changing contract terms, or any other channel through which current inflation affects future price changes.

3. Other influences, such as changes in exchange rates, world prices, or prices of raw materials, can also alter the inflation-unemployment relationship.

The specific equation determining the inflation-unemployment tradeoff is

$$
\frac{\Delta P}{P_{-1}}=a_{0}+a_{1} U^{-m}+\sum_{j=1}^{n} a_{j+1} \frac{\Delta P_{-j}}{P_{-j-1}}+e,
$$

where $U$ is the rate of unemployment, all $a_{j} \geq 0$, and the residual $e$ measures all outside forces that affect inflation independently of unemployment. The long-run tradeoff vanishes if

$$
\sum_{j=1}^{n} a_{j+1}=1 \text {. }
$$

The nonlinearity parameter, $m$, determines the relative short-run impact of low and high unemployment rates in fighting inflation: increases in the un- 
employment rate around 4 percent are always $2^{m+1}$ times as effective in fighting inflation as are increases in the unemployment rate around 8 percent. $^{3}$

The optimal unemployment path for the President concerned only with minimizing rates of inflation for the next five years can be computed by minimizing

$$
\sum_{i=1}^{5} \frac{\Delta P_{i}}{P_{i-1}}+\lambda\left(\sum_{i=1}^{5} U_{i}-5 \bar{U}\right),
$$

where $\lambda$ is the Lagrange multiplier and $\bar{U}$ is the five-year average rate of unemployment. Substituting (2) into (3), finding the minimum point with respect to each $U_{i}$, and solving the system for relative unemployment rates yields

$$
\begin{aligned}
& U_{4} / U_{5}=\sqrt[m+1]{1+a_{2}} \\
& U_{3} / U_{5}=\sqrt[m+1]{1+a_{2}+a_{2}^{2}+a_{3}} \\
& U_{2} / U_{5}=\sqrt[m+1]{1+a_{2}+a_{2}^{2}+a_{3}+a_{2}^{3}+2 a_{2} a_{3}+a_{4}} \\
& U_{1} / U_{5}=\sqrt[m+1]{1+a_{2}+a_{2}^{2}+a_{3}+a_{2}^{3}+2 a_{2} a_{3}+a_{4}+a_{2}^{4}+3 a_{2}^{2} a_{3}+2 a_{2} a_{4}+a_{3}^{2}+a_{5}} .
\end{aligned}
$$

Notice first that the allocation of unemployment over time is independent of the average level, $\bar{U}$. Policymakers use unemployment to root out inflation, and they will proceed with the same time allocation of unemployment for any total dosage. This is true as long as the loss function is not nonlinear in either the level of inflation or unemployment (a condition that would not hold in a more complex analysis).

3. This proposition can be demonstrated as follows: The short-run absolute impact of changes in unemployment in reducing inflation in (2) is

$$
\frac{\partial\left(\Delta P / P_{-1}\right)}{\partial U}=-m a_{1} U^{-(m+1)} \text {. }
$$

With $U_{L}$ and $U_{H}$ denoting low and high unemployment rates, respectively, the relative impact is given by

$$
\frac{\partial\left(\Delta P / P_{-1}\right) / \partial U_{L}}{\partial\left(\Delta P / P_{-1}\right) / \partial U_{H}}=\left(\frac{U_{H}}{U_{L}}\right)^{m+1} .
$$

The relative impact depends only on the ratio between $U_{B}$ and $U_{L}$ and on the nonlinearity parameter, $m$, but is independent of $a_{1}$. 
If all coefficients of lagged price changes $\left(a_{2}, a_{3}, \ldots, a_{n+1}\right)$ are set at zero, so that the short-run tradeoff is totally independent of previous inflation, the solution to each of the relative unemployment relationships equals unity. Policymakers, as expected, would minimize inflation by continually reallocating unemployment from years when its effectiveness in killing inflation is low (that is, those in which its level is high) to years when its effectiveness is high (when the level is low) until all five unemployment rates are equal. But if the lagged coefficients of price changes are not zero, so that the short-run tradeoff is affected by past rates of inflation, an early attack on inflation with high unemployment becomes more important. The solution in this case indicates that unemployment should be greatest in the first year, and diminish with each successive year. This pattern traces a skewed $\mathrm{V}$, or a recession in which the unemployment rate first rises sharply and then falls gradually. ${ }^{4}$ This result obtains even in the absence of specific penalties for rapid reductions in unemployment rates, or "speed limits" as they are now termed. The effective speed limit on this upswing is the fact that each successive year's unemployment rate is increasingly less useful in killing inflation.

The depth of the $\mathrm{V}$ depends positively on both the sum of the pricechange coefficients and the average length of the lag, but negatively on the curvature of the Phillips curve as measured by $m$-because $m$ lowers the relative ability of high unemployment to fight inflation and hence raises the penalty for deviating from a constant path for the unemployment rate. The coefficient for the unemployment rate, $a_{1}$, does not alter this penalty or the optimal solution because, as was shown above, it does not change these relative impacts.

These results can be clarified by the numerical examples given in table 1 . The first column shows the "basic" case, in which all coefficients are taken from an annualized version of the price-wage sector of the SMP econometric model. ${ }^{5}$ This model is accelerationist, with expectations coefficients

4. Although it is not worked out rigorously, the same logic applies to the extraneous inflation residual, $e$. Say that the controlled price of "old" oil (production not in excess of that produced by a well in 1972) has to rise sometime between now and 1980, and that when it rises, it will cause general inflation. Because of the lagged price-change coefficients in the Phillips curve, from a macro standpoint alone this increase in prices should be postponed as long as possible. In the real world, of course, these macro considerations would be balanced against others, such as the short- and long-run response of demand and supply of petroleum to actual and expected price changes.

5. See James L. Pierce and Jared J. Enzler, "The Effects of External Inflationary 
Table 1. The Allocation of Unemployment under Varying Assumptions about the Empirical Relationship between Inflation and Unemployment, and the Administration Projection, 1975-79

\begin{tabular}{|c|c|c|c|c|c|c|}
\hline \multirow[b]{2}{*}{$\begin{array}{l}\text { Ratio } \\
\text { or } \\
\text { year }\end{array}$} & \multicolumn{5}{|c|}{ Assumption } & \multirow[b]{2}{*}{$\begin{array}{l}\text { Adminis- } \\
\text { tration } \\
\text { projection }\end{array}$} \\
\hline & $\begin{array}{l}\text { Basic } \\
\text { case } \\
(S M P \\
\text { model })\end{array}$ & $\begin{array}{c}\text { Fast } \\
\text { accel- } \\
\text { eration of } \\
\text { inflation } \\
\left(a_{2}=1\right. \\
a_{j}=0 \\
\text { for } j \geq 3)\end{array}$ & $\begin{array}{c}\text { No accel- } \\
\text { eration of } \\
\text { inflation } \\
\left(a_{j}=0\right. \\
\text { for } j \geq 4)\end{array}$ & $\begin{array}{c}\text { Sharper } \\
\text { Phillips } \\
\text { curve } \\
(m=2)\end{array}$ & $\begin{array}{c}\text { Flatter } \\
\text { Phillips } \\
\text { curve } \\
(m=0.01)\end{array}$ & \\
\hline & \multicolumn{6}{|c|}{ Ratio between unemployment rates $\left(U_{i} / U_{5}\right)$} \\
\hline$U_{1} / U_{5}$ & 1.50 & 2.23 & 1.33 & 1.31 & 2.27 & 1.30 \\
\hline$U_{2} / U_{5}$ & 1.37 & 2.00 & 1.28 & 1.24 & 1.88 & 1.27 \\
\hline$U_{3} / U_{5}$ & 1.23 & 1.73 & 1.23 & 1.15 & 1.53 & 1.21 \\
\hline \multirow[t]{2}{*}{$U_{4} / U_{5}$} & 1.10 & 1.42 & 1.10 & 1.07 & 1.22 & 1.11 \\
\hline & \multicolumn{6}{|c|}{ Unemployment rate, $U$, assuming five-year average is 7.3 percent } \\
\hline $1975\left(U_{1}\right)$ & 8.86 & 9.73 & 8.20 & 8.31 & 10.53 & 8.1 \\
\hline $1976\left(U_{2}\right)$ & 8.09 & 8.74 & 7.88 & 7.87 & 8.72 & 7.9 \\
\hline $1977\left(U_{3}\right)$ & 7.26 & 7.55 & 7.58 & 7.30 & 7.10 & 7.5 \\
\hline $1978\left(U_{4}\right)$ & 6.49 & 6.20 & 6.78 & 6.78 & 5.66 & 6.9 \\
\hline $1979\left(U_{5}\right)$ & 5.90 & 4.37 & 6.16 & 6.34 & 4.64 & 6.2 \\
\hline
\end{tabular}

Sources: For the assumptions, the general form of the equation is

$$
\frac{\Delta P}{P_{-1}}=a_{0}+a_{1} U^{-m}+\sum_{j=1}^{6} a_{j+1} \frac{\Delta P_{-j}}{P_{-j-1}}+e,
$$

where $P$ is the general price level, $U$ is the rate of unemployment, and $m$ is a parameter establishing the relative impact of high and low unemployment rates. Unless otherwise stated, the following coefficients from the SMP model are used: $\mathrm{m}=1, a_{2}=0.22, a_{3}=0.26, a_{4}=0.23, a_{5}=0.17, a_{6}=0.09, a_{7} \times 0.03$. The administration projection is from The Budget of the United States Government, Fiscal Year 1976, p. 41. The ratios are calculated from data before rounding.

$a_{2}$ through $a_{7}$ summing to unity. Like most econometric relationships, it assumes that $m=1$. The optimal path for unemployment, under the assumption that the five-year average of the unemployment rate is the same 7.3 percent as in the administration's long-run projection, involves a rate of 8.9 in $1975,8.1$ in 1976, and so on down to 5.9 in 1979 . The 1975 rate is then 3 points above the 1979 rate. The pattern of unemployment has a more definite $\mathrm{V}$ shape than the path contained in the long-run projection pro-

Shocks," BPEA (1:1974), pp. 19-29. The model was annualized by computing the quarterly reduced-form response of prices to all independent variables, and then taking annual averages of these responses. 
vided by the administration at the first of the year, which is shown in the last column of the table. ${ }^{6}$ These numbers imply an average annual rate of growth of real GNP of about 6.5 percent over the 1975-79 period, high by historical standards but still consistent with the speed limit implicit in this model.

The other cases shown in table 1 vary the parameters of the inflationunemployment relationship in ways discussed above. If the acceleration of inflation took place more quickly-say, with $a_{2}=1$ and all other lagged price-change coefficients equal to zero-an immediate and sharp recession would have much more value: the optimal unemployment rate for the first year becomes 9.7 percent. If there were no acceleration of inflation-say, with all price-change coefficients but the first two set equal to zero, an immediate recession would have less value and the first year's unemployment rate is 8.2. Apart from this difference, however, the optimal paths with and without acceleration are quite similar, indicating that the mean of the lag distribution influences the results much more than the sum of the lag coefficients. A pattern similar to that with no acceleration emerges when the SMP expectations coefficients are restored but with more curvature in the Phillips curve $(m=2)$ : again unemployment should be more evenly distributed than in the basic case. For what it is worth, both of these paths are very close to those projected in the budget document. On the other hand, the $\mathrm{V}$ becomes very sharp, even more so than in the case of quick acceleration, if the curvature in the Phillips curve is reduced by setting $m$ very close to zero (see the last assumption in table 1 ). ${ }^{7}$

6. After the 1976 budget document was released, the unemployment rate rose so rapidly that the standard forecast now puts the unemployment rate for 1975 at about 8.8 percent. If administration policymakers were trying to hold the five-year average at 7.3 percent, they would now implicitly be following a path much closer to the optimal one of table 1 . If the five-year average rate of unemployment is raised by $0.7(8.8-8.1)$, the profile of the recession remains suboptimal in this sense.

7. It is impossible to set $m$ exactly equal to zero because then unemployment ceases to have an effect on inflation and the whole analysis breaks down. However, as $m$ approaches zero, the relative impact of high and low unemployment rates in fighting inflation approaches $\left(U_{H} / U_{L}\right)$, the same value as when the rate of inflation depends on the logarithm of unemployment. This can be seen when (2) is rewritten as

$$
\frac{\Delta P}{P}=a_{0}-c \ln U+\ldots
$$

The absolute impact of changes in unemployment in reducing inflation is then

$$
\frac{\partial(\Delta P / P)}{\partial U}=\left(\frac{\partial(\Delta P / P)}{\partial \ln U}\right)\left(\frac{\partial \ln U}{\partial U}\right)=-c U^{-1},
$$




\section{Minimizing Rates of Inflation for Five Years and Beyond}

Now assume that this President resigns and is succeeded by one who, while he has nothing against minimizing inflation for the next five years, does not want to burden his successor with an inflation-prone economy either. He correctly perceives that the strategy followed by his own predecessor ignores a very important point: that restricting the minimization to a five-year period does not penalize actions that may lead to inflation-perhaps accelerating inflation-beyond that horizon. The same reasoning suggests that those paths of table 1 that leave the economy in noninflationary equilibrium in year 5 are suboptimal, because they imply excessive amounts of unemployment in the first five years. If the economy will end up at some noninflationary rate of unemployment ultimately, it is not as important to generate high unemployment immediately.

The loss function for the new President includes, with some utility weight, rates of inflation outside of the five years he will be in office. The President makes unemployment-rate policy for only five years, but he tries to make it in such a way that he bequeathes a less inflation-prone economy to his successor, and hence one that can enjoy lower unemployment rates and higher consumption levels. In this sense the inflation-unemployment choices of this President are analogous to the consumption-investment choices he also makes during his regime.

The optimal unemployment path for this more farsighted President can be computed by minimizing

$$
\sum_{i=1}^{\infty} b_{i} \frac{\Delta P_{i}}{P_{-i-1}}+\lambda\left(\sum_{i=1}^{5} U_{i}-5 \bar{U}\right),
$$

where $b_{i}$ is the utility weight the President attaches to reducing inflation in any future year. For the former, more myopic, President, the first five $b_{i}$ were one (equation 3 ) and all others were zero. If that President had had a longer horizon, more $b_{i}$ would equal one and fewer would equal zero. If he had an infinite horizon but an implicit time-preference discount rate of $r$,

and the relative impact reduces to $\left(U_{H} / U_{L}\right)$. The logarithmic form approximates that used by Robert E. Hall, "The Process of Inflation in the Labor Market," BPEA (2:1974), p. 366, and derived by Charles C. Holt and others, The Unemployment-Inflation Dilemma: A Manpower Solution (Urban Institute, 1971), p. 100. 
each $b_{i}$ would equal

$$
\left(\frac{1}{1+r}\right)^{i-1}
$$

If he had an infinite horizon with no time preference at all, each $b_{i}$ would equal unity. 8

The optimal allocation of unemployment for this new President is determined just as before. The analytical solution becomes very lengthy and is not given here, but an approximate numerical solution for the SMP model is

(6) $U_{4} / U_{5}$

$$
=\sqrt{\left(b_{4}+0.22 b_{5}+0.31 b_{6}+0.36 \sum_{i=7}^{\infty} b_{i}\right) /\left(b_{5}+0.22 b_{6}+0.31 b_{7}+0.36 \sum_{i=8}^{\infty} b_{i}\right)}
$$

$U_{3} / U_{5}$

$=\sqrt{\left(b_{3}+0.22 b_{4}+0.31 b_{5}+0.36 \sum_{i=6}^{\infty} b_{i}\right) /\left(b_{5}+0.22 b_{6}+0.31 b_{7}+0.36 \sum_{i=8}^{\infty} b_{i}\right)}$

$U_{2} / U_{5}$

$=\sqrt{\left(b_{2}+0.22 b_{3}+0.31 b_{4}+0.36 \sum_{i=5}^{\infty} b_{i}\right) /\left(b_{5}+0.22 b_{6}+0.31 b_{7}+0.36 \sum_{i=8}^{\infty} b_{i}\right)}$

$U_{1} / U_{5}$

$=\sqrt{\left(b_{1}+0.22 b_{2}+0.31 b_{3}+0.36 \sum_{i=4}^{\infty} b_{i}\right) /\left(b_{5}+0.22 b_{6}+0.31 b_{7}+0.36 \sum_{i=8}^{\infty} b_{i}\right)}$.

8. Discounting of future inflation can also be thought of as a way of dealing with the complication that arises because inflation has both anticipated and unanticipated components. Assume that inflation is harmful only if it is unanticipated, and that policymakers want to minimize it only because it is proceeding at rates above the anticipated (optimal) level. If $r$ measured the degree to which anticipations adjusted upward in response to a gap between actual and anticipated inflation rates, this gap would then be lessened, and inflation would become less harmful, at the rate of $r$ percent per year. In this sense, it does not matter whether $r$ reflects the gradual adjustment of anticipated to actual inflation or the time-preference discounting of future inflation.

In a similar vein, future rates of unemployment could also be discounted. On the one hand, unemployment now is more damaging than unemployment later because of the lost productivity of the missed investment; on the other hand, it is more damaging later, when more people will be unemployed and more absolute damage will have occurred. If, as seems likely, the rate of return on capital is above the rate of growth of the labor force corrected for labor-augmenting technology, the net effect of these forces would be to make present unemployment more damaging and to smooth out to some degree the $\mathrm{V}$ along the optimal path (thus working in the same direction as the discounting of future inflation). In this model the importance of unemployment discounting will never be great, however, because I assume that the President is making unemployment policy, and hence comparing the cost of unemployment, for five years only. 
Table 2. The Allocation of Unemployment under Varying Assumptions about the Time Horizon for Reducing Inflation

Ratios between unemployment rates $\left(U_{i} / U_{5}\right)$

\begin{tabular}{lccccccc}
\hline & \multicolumn{2}{c}{$\begin{array}{c}\text { Zero rate of time preference } \\
\text { for } n \text { years }\end{array}$} & & \multicolumn{3}{c}{$\begin{array}{c}\text { Infinite horizon, time preference } \\
\text { rate of } r\end{array}$} \\
\cline { 2 - 3 } \cline { 7 - 8 } Ratio & $n=5$ & $n=10$ & $n=\infty$ & & $r=0.20$ & $r=0.10$ & $r=0.05$ \\
\hline$U_{1} / U_{5}$ & 1.50 & 1.24 & 1.00 & & 1.44 & 1.20 & 1.11 \\
$U_{2} / U_{5}$ & 1.37 & 1.18 & 1.00 & & 1.31 & 1.15 & 1.08 \\
$U_{3} / U_{5}$ & 1.23 & 1.13 & 1.00 & & 1.21 & 1.10 & 1.05 \\
$U_{4} / U_{5}$ & 1.10 & 1.06 & 1.00 & & 1.10 & 1.05 & 1.02 \\
\hline
\end{tabular}

Source: Equation (6) discussed in the text; $U_{1}, \ldots, U_{5}=$ the unemployment rates in 1975 through 1979.

The corresponding optimal paths are given in table 2. The table shows first how the V-shaped recession is spread out as the time horizon is lengthened for a President with no implicit time-preference rate, or as the implicit rate of time preference is reduced for a President with an infinite horizon. For either case, only a modest degree of farsightedness brings about a sizable reduction in the amplitude of the V-shaped recession. Table 2 does not give absolute levels of the unemployment rate because presumably the dose of unemployment administered to kill inflation would also depend on the President's time horizon. If, for example, the President had no time preference at all and an infinite horizon, the nation need experience only slightly more unemployment than the natural rate in the first five years.

\section{How Much Can Inflation (Unemployment) Be Reduced?}

The previous sections have described the optimal path of unemployment in a recession and have shown how it would vary with empirical magnitudes and with the time preference of the President with regard to killing inflation. But they have not addressed the issue of how important it might be to follow the optimal path for the unemployment rate. The question is how much more will inflation be reduced in the strategy laid out in the basic case of table 1-the optimal strategy for a nearsighted President who believes the SMP model-as contrasted with a strategy that simply keeps the unemployment rate in each year equal to the five-year average- the optimal strategy for the most farsighted of Presidents, who is not concerned with 


\section{Table 3. Yearly Unemployment Rates and Average Annual Rates} of Inflation for Various Unemployment Strategies, 1975-79

Percent

\begin{tabular}{llccc}
\hline & \multicolumn{4}{c}{ Average unemployment rate } \\
\cline { 2 - 5 } Year or strategy & $5 \%$ & $6 \%$ & $7 \%$ & $8 \%$ \\
\hline & \multicolumn{3}{c}{ Unemployment rate, } & U, along the optimal path \\
$1975\left(U_{1}\right)$ & 6.05 & 7.26 & 8.48 & 9.68 \\
$1976\left(U_{2}\right)$ & 5.52 & 6.63 & 7.74 & 8.84 \\
$1977\left(U_{3}\right)$ & 4.96 & 5.95 & 6.95 & 7.93 \\
$1978\left(U_{4}\right)$ & 4.43 & 5.32 & 6.22 & 7.10 \\
$1979\left(U_{5}\right)$ & 4.03 & 4.84 & 5.65 & 6.45 \\
& \multicolumn{4}{c}{ Five-year average annual rate of increase of } \\
& 6.48 & 5.52 & 4.82 & 4.24 \\
$U_{i}$ follow optimal path & 6.62 & 5.62 & 4.94 & 4.36 \\
All $U_{i}$ equal & \multicolumn{4}{c}{ Reduction in inflation along optimal path } \\
& 0.14 & 0.10 & 0.12 & 0.12 \\
\hline
\end{tabular}

Source: Simulation of the price-wage sector of the SMP model, as discussed in the text.

a. Inflation rates are computed from fourth quarter of 1974 to fourth quarter of 1975 , and so forth for five years.

the price-change coefficients in the Phillips curve as long as he knows the relationship is nonlinear.

These comparisons are made by simulating the price-wage sector of the SMP model for the next five years, holding unemployment at its specified value and the few other exogenous impact variables in it (unfilled orders, prices of raw materials, and so on) at plausible values. Table 3 gives specific values of the unemployment rate for each five-year average rate, using the optimal allocation described in the basic case of table 1 . The bottom panel gives the average annual inflation rate of the private nonfarm deflator over the five-year period along this optimal path, and then compares this rate with one that would obtain if all $U_{i}$ are held at the five-year average. ${ }^{9}$

Granted that all empirical price-wage relationships should be treated with skepticism these days, the table does contain some suggestive findings. First, because of the continuing force of already experienced inflation, even

9. In order to exclude from this comparison the large amount of inflation that occurred in the fourth quarter of 1974, I have shown average rates of inflation from fourth quarter to fourth quarter, beginning in 1974 and extending for five years. I have also assumed no oil-price increase and no other exogenous source of inflation. 
this accelerationist Phillips curve predicts that inflation will be checked relatively little by higher unemployment rates: if unemployment averages 6 percent or more for the next five years-which it almost certainly will, given the high unemployment rates now in prospect for 1975 and 1976-an increase in this average unemployment rate of 1 percentage point will lower the average inflation rate by only about 0.6 percentage point. The improvements from following the optimal strategy are, in an absolute sense, very slight, amounting to only 0.12 percentage point across the four cases. But these improvements are slight partly because inflation is already so insensitive to unemployment in these ranges: if five-year changes in the unemployment rate offer only small amelioration of inflation, one-year changes could hardly be expected to do better. It may be more meaningful to compare the reduction in inflation from following the optimal path $(0.12)$ with that from letting the unemployment rate rise by 1 percentage point $(0.6)$. In this sense, following the optimal path allows the unemployment rate to be lower by an average of 0.2 percentage point over the next five years, or by 0.1 percentage point as contrasted with the projection in the budget document. Using the standard Okun's law conversion, a reduction of 0.2 percentage point in the unemployment rate equals a 0.6 percent increase in GNP- $\$ 10$ billion at today's prices-in each of the five years.

These results can be viewed in a different way, more relevant to current problems. The unemployment rate for 1975, the first year of this exercise, now is likely to be very close to the 8.86 percent average computed for the optimal path with the administration's five-year total amount of unemployment. If this high unemployment in the first year does its job of killing inflation, it permits a reduction in the average rate of unemployment for the next four years of approximately 0.3 percentage point-or $\$ 15$ billion in GNP per year-to achieve the same average rate of inflation that is implied by the administration's unemployment projection. Having taken a stiff dose of its anti-inflationary medicine already, the economy needs less of it altogether.

\section{Conclusion}

The theoretical message here is that if the economy needs periodic unemployment to kill inflation, it is usually better to submit to a heavier burden early and allow the recovery to proceed in a more noninflationary environ- 
ment later on. The precise pattern for unemployment will then depend both on the empirical relationship between inflation and unemployment-particularly on the way in which this relationship has shifted with past inflation-and on the haste with which policymakers feel they must kill inflation. The empirical message is that, since variations in unemployment in the neighborhood of its present high level do not make much difference for inflation, neither does the timing of unemployment. Although the amounts involved between optimal and suboptimal paths are thus not of earthshaking importance, this exercise indicates that now that the economy has already taken so much unemployment, it can take at least a fairly strong recovery.

\section{Discussion}

Several comments dealt with the specification of Gramlich's model. Stephen Goldfeld called attention to its ignoring of uncertainty. He noted that, in fact, policy was likely to be influenced by uncertainty about the error term of the equation, about the size of the effects of past inflation and unemployment on current inflation, and about the link between the fiscal-monetary policy instruments and the unemployment rate. James Pierce added that the uncertainty about the relationship among current inflation, unemployment, and past inflation was clearly a major factor in policy planning these days. A model that uses point estimates of these relations in a certainty-equivalence framework may not provide much insight into the real problem. Saul Hymans and Franco Modigliani were concerned that the initial level of unemployment has no impact either on the average unemployment to be aimed for over the decision period or on the allocation of the average unemployment over time. They would have preferred a model in which both these dimensions of the optimal time path depended on initial conditions. In relation to this point, Charles Holt objected that the linear criterion function Gramlich used was unrealistic. A nonlinear function would be more appropriate since the concern of policymakers appears to increase proportionately more than does the inflation or the unemployment rate.

R. J. Gordon interpreted Gramlich's results as saying that alternative 
time paths for unemployment offer little choice, given a slope of the shortrun Phillips curve as flat as that in the SMP model. He also judged that inflation was currently slowing more quickly than that model would predict. It was too early to tell whether this inaccuracy meant that inflation was responding faster to recession than the normal wage and price equations would predict or that the model forecast failed to recognize how much of last year's price increase was a one-shot affair that would abate automatically. Holt disagreed that there was little to choose among the alternative paths presented by Gramlich. He felt that a $\$ 10$ billion annual gain in GNP from following the optimal unemployment path should be significant in influencing policy and added that the gain from optimality would appear even larger if a nonlinear criterion function were used. Holt was concerned by the paper's evidence that aggregate-demand approaches to fighting inflation are very costly in terms of the unemployment necessary to achieve a slowdown. He suggested that economists should be examining new alternatives to traditional aggregate-demand instruments. And he proposed that ways to wind down inflation more quickly might be found through changes that reduced the time lags in the wage-price adjustment processes.

George Perry and Arthur Okun thought that the purpose of the Gramlich paper was not to determine empirically the optimal shape for a recession to curb inflation, but rather to illustrate a qualitative point. One conclusion sometimes inferred from the nonlinearity of the Phillips curve is that unemployment should always be maintained at an average level. Gramlich demonstrates that since killing some inflation today also kills some inflation tomorrow, it pays to take more unemployment today and less tomorrow.

Some confusion arose over the meaning of the estimates of the unemployment rates for 1976-80 that Gramlich used and that had appeared in the budget documents. Some read these as statements of the administration's targets. But William Fellner stressed that the projections were not intended as forecasts or as recommendations. He insisted that, in explaining its economic assumptions, the administration had stated explicitly that the projections were not an administration goal, since policy decisions affecting the time path would be made in response to economic conditions that cannot be forecast over so long a period. 